\title{
Effects of preoperative mental distress versus surgical modality, arthroplasty, or fusion on long-term outcome in patients with cervical radiculopathy
}

\author{
Anna MacDowall, MD, PhD, ${ }^{1}$ Martin Skeppholm, MD, PhD, ${ }^{2,3}$ Lars Lindhagen, ${ }^{4}$ \\ Yohan Robinson, MD, PhD, ${ }^{1}$ and Claes Olerud, MD, $\mathrm{PhD}^{1}$ \\ 1Department of Surgical Sciences, Uppsala University, Uppsala; '2Department of Learning, Informatics, Management and \\ Ethics (LIME), Medical Management Center, Health Economics and Health Evaluation Research Group, Karolinska Institutet, \\ Stockholm; ${ }^{3}$ Center for Spine Surgery in Stockholm, Sophiahemmet Sjukhus, Stockholm; and 4 Uppsala Clinical Research \\ Center, Uppsala University, Uppsala, Sweden
}

\begin{abstract}
OBJECTIVE Several efforts have been made to investigate the long-term efficacy of artificial disc replacement surgery compared with that of fusion after decompression for the treatment of cervical degenerative disc disease and radiculopathy. However, research on the impact of mental distress on surgical treatment outcome has been sparse. The aim of the authors was to investigate the potential predictive value of preoperative risk factors in determining long-term outcome.

METHODS A total of 153 patients (mean age 47 years) with single- or double-level cervical degenerative disc disease and radiculopathy were randomly assigned to undergo either anterior cervical discectomy and fusion $(n=70)$ or artificial disc replacement $(n=83)$. The primary outcome was the Neck Disability Index (NDI) score, a patient-reported function score that ranges from $0 \%$ to $100 \%$; higher scores indicate greater disability. Preoperative variables such as sex, age, smoking status, employment status, having a strenuous job, neck pain duration, arm pain duration, amount of regular exercise, Hospital Anxiety and Depression Scale (HADS) score, NDI score, whether surgery was performed on 1 or 2 levels, and allocated treatment were analyzed in multiple linear regression models with the 5 -year NDI score as the outcome.
\end{abstract}

RESULTS A total of $47(31 \%)$ patients had either a HADS anxiety or HADS depression score of 10 points or higher. High values on the preoperative HADS were a negative predictor of outcome $(p=0.009)$. Treatment allocation had no effect on 5 -year NDI scores $(p=0.32)$.

CONCLUSIONS Preoperative mental distress measured with the HADS affects long-term outcome in surgically treated patients with cervical radiculopathy.

https://thejns.org/doi/abs/10.3171/2018.2.SPINE171378

KEYWORDS artificial disc replacement; Hospital Anxiety and Depression Scale; treatment outcome; Neck Disability Index; cervical radiculopathy

$\mathrm{C}$ ERVICAL radiculopathy is characterized by radiating pain from the neck to the shoulder, shoulder blade, arm, or hand and is typically the consequence of degenerative changes such as disc herniation and osteophyte formation; lower cervical segments are affected most frequently. ${ }^{19}$ Most patients with cervical radiculopathy recover after nonsurgical treatment, but persistent pain and patient expectations can motivate surgical intervention. ${ }^{39}$ The most common surgical treatment procedure is anterior decompression and fusion (more than 100,000 patients in the United States undergo such surgery each year). ${ }^{26}$ However, in recent years, artificial disc replacement (ADR) has become an alternative approach. ${ }^{8}$ Several investigational device exemption studies have found clinical noninferiority in comparisons of ADR devices and fusion surgery. ${ }^{6,9,31}$ Even after surgery with decompression of the affected nerve, some patients do not improve or benefit from it. Studies of predictive factors have reported differ-

ABBREVIATIONS ADR = artificial disc replacement; EQ-5D = EuroQol-5 Dimensions; $H A D S=$ Hospital Anxiety and Depression Scale; ITT = intention to treat; $M C I D=$ minimum clinically important difference; NDI = Neck Disability Index; $P R O M=$ patient-reported outcome measure; $R C T=$ randomized controlled trial; VAS = visual analog scale.

SUBMITTED December 13, 2017. ACCEPTED February 19, 2018.

INCLUDE WHEN CITING Published online July 13, 2018; DOI: 10.3171/2018.2.SPINE171378. 
ent variables that affect treatment outcome, ${ }^{3,11,16}$ such as preoperative mental distress, which has been found to be a predictor of negative short-term outcome after surgical treatment for cervical radiculopathy. ${ }^{37}$ Long-lasting pain can affect psychological/psychosocial factors and can be a mental burden to patients, which predisposes them to developing anxiety and/or depression. ${ }^{14}$ In contrast, anxiety and depressive disorders, as well as passive coping, can affect patient perception of and susceptibility to pain. ${ }^{4,25,41}$ For lumbar conditions, comprehensive research has established emotional dysfunction, depression, anxiety, fear, and heightened anger as risk factors for poor surgical outcome, ${ }^{5}$ but for the cervical spine, such research has been sparse. To our knowledge, the role of anxiety and depression assessed using the Hospital Anxiety and Depression Scale (HADS) as the screening tool in long-term outcome after surgical treatment of cervical radiculopathy has not been investigated.

The aim of our study was to investigate the potential predictive value of preoperative risk factors in 5-year outcomes after surgery for cervical radiculopathy.

\section{Patients and Methods}

\section{Trial Design}

We conducted a multicenter randomized clinical superiority trial in which patients with cervical radiculopathy were assigned randomly to undergo either unconstrained ADR using a Discover cervical disc prosthesis (DePuy Spine, Johnson \& Johnson) or fusion using autologous iliac crest graft and plate fixation after decompression. We enrolled patients with cervical radiculopathy aged 25-60 years who met the inclusion criteria (Table 1). According to company guidelines, an ADR device is not recommended for patients with osteoporosis. Therefore, patients with a known diagnosis of osteoporosis or previous osteoporotic fractures and elderly patients ( $>60$ years old) were excluded. Enrollment of patients took place at 3 Swedish study centers between 2007 and 2011.

Details of the randomization process and results from the 2 years of follow-up have been published previously. ${ }^{36}$ In brief, after surgical exposure and decompression were completed, simple 1:1 randomization without blocks was performed using a closed-envelope technique. Hence, both the patient and the surgeon were blinded until decompression was completed and instruments for both ADR and fusion were prepared in the operating room. The ADR group was treated with nonsteroidal anti-inflammatory drugs for 10 days after surgery; otherwise, the postoperative regime was the same in both groups. No collar or restrictions were used in either group. All the participating surgeons were highly experienced in performing both trial interventions.

\section{Trial Oversight}

The trial was approved by the local Swedish ethics review board, and each participant provided oral and written informed consent. This study was based on data from the original randomized controlled trial (RCT). The study was registered in the ISRCTN registry (No. 44347115).

\section{Data Collection and Outcomes}

The patients completed baseline characteristic questionnaires, postal follow-up questionnaires, and validated patient-reported outcome measures (PROMs) without any assistance from the surgeon. Preoperative data collected included age, sex, length, weight, smoking habits, exercising habits, working status, sick leave status, duration of neck pain, use of analgesics, and PROMs, including Neck Disability Index (NDI) score, ${ }^{28}$ EuroQol-5 Dimensions (EQ-5D), and the 10-point visual analog scale (VAS)-neck and VAS-arm. The surgeons recorded data including diagnosis, surgical treatment method, surgical levels involved, neurological impairment, Ranawat scale score, ${ }^{33}$ Frankel grade, ${ }^{13}$ instability of the cervical spine, type of implant, and eventual perioperative complications. Follow-up and PROM questionnaires were sent to the patients 4 weeks, 3 months, and 1,2, and 5 years after surgery.

The primary outcome, NDI score, is a 10-item selfadministered questionnaire that measures disability in patients with neck pain. The questions measure the ability to perform daily activities (e.g., to dress, lift heavy objects, read, work, drive a car, sleep, and perform leisure-time activities), concentration abilities, and severity of pain and

TABLE 1. Inclusion and exclusion criteria

\begin{tabular}{ll}
\hline \multicolumn{1}{c}{ Inclusion Criteria } & \multicolumn{1}{c}{ Exclusion Criteria } \\
\hline Age 25-60 yrs & Previous cervical spine surgery \\
\hline $\begin{array}{l}\text { Symptoms of radiating arm pain with a duration } \\
\text { of at least 3 mos }\end{array}$ & $>2$ cervical levels requiring treatment \\
\hline $\begin{array}{l}\text { Correlating findings on MRI on 1 or 2 cervical } \\
\text { levels }\end{array}$ & Visible or severe osteoarthritis in facet joints evaluated preoperatively on plain radiographs and MRI \\
\hline $\begin{array}{l}\text { Eligible for both treatments } \\
\text { Ability to understand and read Swedish language }\end{array}$ & Drug abuse, dementia, or other reason to suspect poor adherence to follow-up \\
\hline & Cervical malformation or marked cervical instability \\
\hline & History of whiplash-associated disorder or severe cervical trauma \\
\hline & Pregnancy \\
\hline & Rheumatoid arthritis, known malignancy, active infection, or other systemic disease \\
\hline & $\begin{array}{l}\text { Known allergy or hypersensitivity to any of the constituent materials of the implants or to nonsteroi- } \\
\text { dal antiinflammatory drugs }\end{array}$ \\
\hline
\end{tabular}




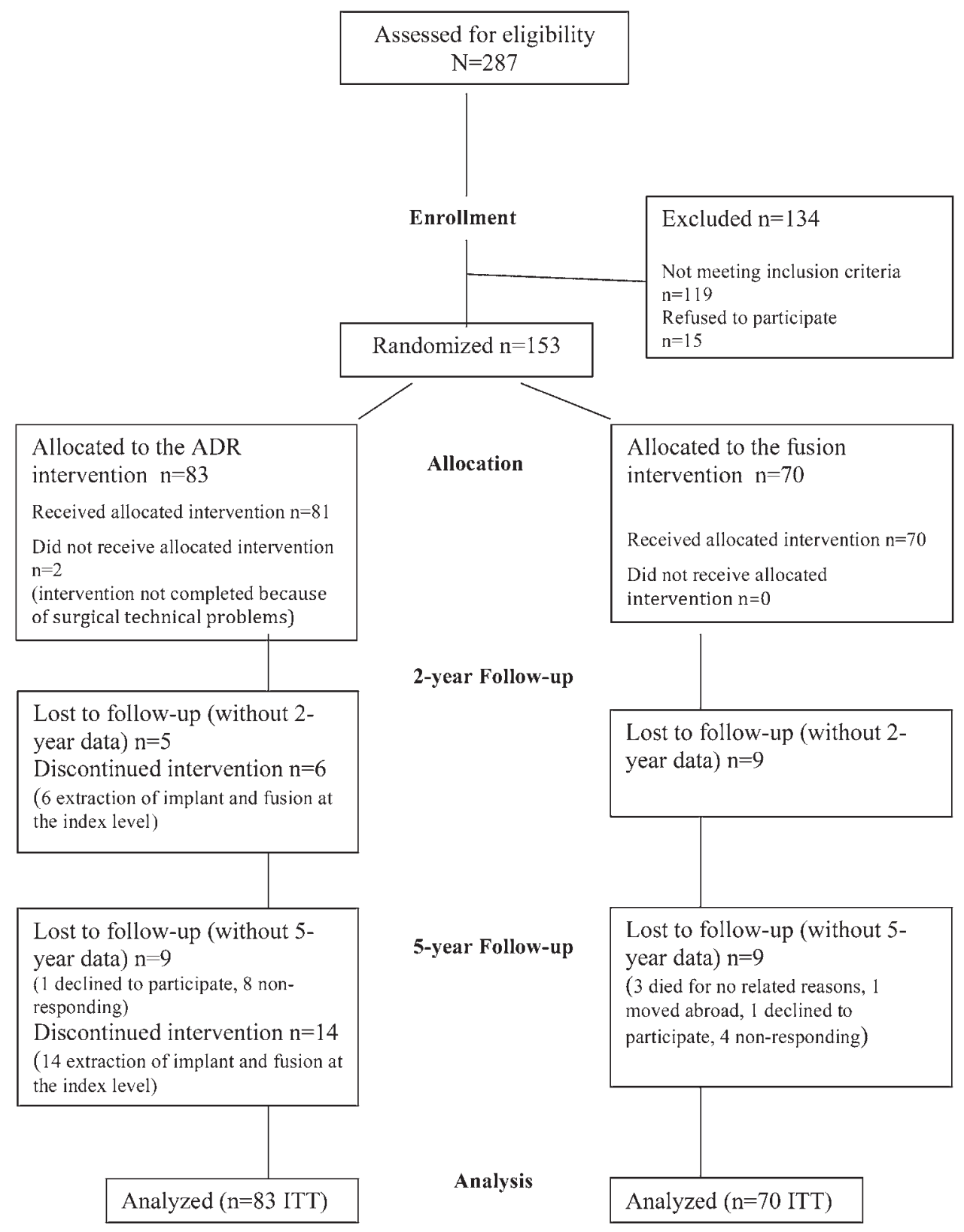

FIG. 1. Consort diagram.

headache. Each item is scored from 0 to 5 . The maximum score is 50 points, which indicates severe disability, and the minimum score is 0 , which indicates no disability. The score we used was transformed to a percentage (score of 100 ) by doubling the total score (range 0\%-100\%). The minimum clinically important difference (MCID) is $15 \%-$ $17.3 \% .^{7,44}$

Secondary outcomes were the EQ-5D (range 0.0-1.0, higher scores reflect better quality of life) ${ }^{40}$ and VASs for neck and arm pain ${ }^{23}$ (range $0-100 \mathrm{~mm}$, higher scores indicate more severe pain). The MCIDs are $21 \mathrm{~mm}$ for the VAS-neck and $29 \mathrm{~mm}$ for the VAS-arm. ${ }^{23}$

The HADS was used to assess the prevalence of anxiety (HADS-a) and depression (HADS-d) before surgery. The $\mathrm{HADS}^{45}$ is a 14 -item instrument with 7 questions that concern anxiety (HADS-a) and 7 that concern depression (HADS-d). Every item is scored on a 4-point scale from 0 to 3 , and scores for each subscale range from 0 to 21 ; the highest total score is 42 . It is a validated tool in medical practice for screening psychological distress in non-psychiatric patient populations. ${ }^{18,27}$ Falavigna et al. ${ }^{12}$ found that a HADS-d cutoff score of $\geq 10$ points in patients undergoing spine surgery resulted in a sensitivity of $71 \%$ and a specificity of $95 \%$.

\section{Statistics}

We calculated that a minimum of 102 patients would be required for a superiority trial to have $80 \%$ power with $\alpha$ $=0.05$ to detect an MCID in the NDI scores between the treatment groups of at least 10 points. ${ }^{22,32,38}$ To make up for 
TABLE 2. Baseline patient demographics stratified according to randomized group

\begin{tabular}{|c|c|c|c|c|}
\hline Patient Characteristics & No. & $\operatorname{ADR}(n=83)$ & Fusion $(n=70)$ & Total $(n=153)$ \\
\hline Sex (no. [\%]) & 153 & & & \\
\hline Female & & $41(49.4)$ & $37(52.9)$ & $78(51.0)$ \\
\hline Male & & $42(50.6)$ & $33(47.1)$ & $75(49.0)$ \\
\hline Age in yrs (mean \pm SD) & 153 & $47 \pm 6.8$ & $47 \pm 6.9$ & $47.0 \pm 6.9$ \\
\hline Treatment (no. [\%]) & 153 & $83(54.2)$ & $70(45.8)$ & 153 \\
\hline Body mass index (mean) & 151 & $26[2]$ & 26 & 26 \\
\hline Smoker (no. [\%]) & 149 & $26(31.7)[1]$ & $21(31.3)[3]$ & $47(31.5)[4]$ \\
\hline Pension (no. [\%]) & 148 & $1(1.2)[1]$ & $0(0.0)[4]$ & $1(0.7)[5]$ \\
\hline Unemployed (no. [\%]) & 149 & $8(9.8)[1]$ & $10(14.9)[3]$ & 18 (12.1) [4] \\
\hline Sick leave (no. [\%]) & 148 & $56(68.3)[1]$ & $44(66.7)[4]$ & $100(67.6)[5]$ \\
\hline Disability pension (no. [\%]) & 143 & $42(53.8)[5]$ & $31(47.7)[5]$ & $73(51.0)[10]$ \\
\hline Heavy work (no. [\%]) & 148 & $72(87.8)[1]$ & $54(81.8)[4]$ & $126(85.1)[5]$ \\
\hline Neck pain duration (no. [\%]) & 149 & & & \\
\hline$<3$ mos & & $2(2.4)[1]$ & $1(1.5)[3]$ & $3(2.0)[4]$ \\
\hline $3-12$ mos & & $15(18.1)$ & $19(27.1)$ & $34(22.2)$ \\
\hline $1-2$ yrs & & $20(24.1)$ & $18(25.7)$ & $36(24.2)[4]$ \\
\hline$>2$ yrs & & $40(48.2)$ & $29(41.4)$ & $69(46.3)[4]$ \\
\hline Arm pain duration (no. [\%]) & 149 & [1] & [3] & [4] \\
\hline$<3$ mos & & $3(3.6)$ & $3(4.3)$ & $6(4.1)$ \\
\hline $3-12$ mos & & $20(24.1)$ & $23(32.9)$ & $43(28.9)$ \\
\hline $1-2$ yrs & & $31(37.3)$ & $17(24.3)$ & $48(32.2)$ \\
\hline$>2$ yrs & & $26(31.3)$ & $24(34.3)$ & $50(33.6)$ \\
\hline Regular exercise (no. [\%]) & 147 & $35(42.2)[3]$ & $18(25.7)[3]$ & $53(36.1)$ \\
\hline HADS score (mean \pm SD) & 149 & & & \\
\hline Depression & & $5.0 \pm 3.5[3]$ & $4.7 \pm 3.7[1]$ & $4.9 \pm 3.6$ \\
\hline Anxiety & & $7.0 \pm 4.2[3]$ & $7.0 \pm 4.1[1]$ & $7.0 \pm 4.1$ \\
\hline Total & & $12.0 \pm 7.0[3]$ & $11.8 \pm 7.1[1]$ & $11.9 \pm 7.0$ \\
\hline NDI score (mean \pm SD) & 149 & $63.9 \pm 16.6[1]$ & $61.5 \pm 14.5[3]$ & $62.8 \pm 15.7$ \\
\hline Levels (no. [\%]) & 153 & & & \\
\hline 1 & & $55(66.3)$ & $50(71.4)$ & $105(68.6)$ \\
\hline 2 & & $28(33.7)$ & $20(28.6)$ & $48(31.4)$ \\
\hline
\end{tabular}

Percentages were computed by group. Values in square brackets indicate the number of missing patients.

crossovers and noncompliance, the final sample included 153 patients.

PROMs were analyzed primarily as intention to treat (ITT) and included all randomly assigned patients. Missing values were imputed with multiple imputation using chained equations as implemented in the $\mathrm{R}$ package $\mathrm{MICE}^{43}$ with 20 iterations. A multiple linear regression model was fit to imputed data by using the 5-year NDI score as the outcome and variables from the baseline data as predictors. The predictors were selected based on present knowledge and the directed acyclic graph ${ }^{17}$ approach: sex, age (continuous), allocated treatment (fusion vs arthroplasty), smoking status (current vs no present smoking), retirement pension status (yes vs no), unemployment status (yes vs no), sick leave status (yes vs no), disability pension status (yes vs no), having a strenuous job (yes vs no based on the patients own opinion [strenuous was defined as heavy lifting]), neck pain duration ( $<3$ months, 3-12 months, $1-2$ years, or $>2$ years), arm pain duration
( $<3$ months, 3-12 months, $1-2$ years, or $>2$ years), amount of exercise (regular exercise $>1$ /week, yes vs no), preoperative HADS-a score (continuous), preoperative HADS-d score (continuous), preoperative NDI score (continuous), and levels of surgery performed (1 or 2). A second analysis was made in which the HADS-a and HADS-d scores were replaced with the HADS-total score but otherwise with the same variables. Regression coefficients together with $95 \%$ confidence intervals (CIs) and p values were calculated for the null hypothesis of no predictive effect on outcome (coefficient $=0$ ).

HADS scores were dichotomized into the high-HADS group if either the anxiety or depression score was $\geq 10$ points and the low-HADS group if the anxiety and depression scores were $<10$ points, based on Falavigna et al. ${ }^{12,37}$ Using ANCOVA (analysis of covariance), we calculated the mean 5-year outcome value for each HADS group (high and low) adjusted for baseline values of the outcome. The mean differences of the 5-year values between the 
TABLE 3. Patient demographics at baseline stratified according to HADS score group

\begin{tabular}{|c|c|c|c|c|}
\hline Patient Characteristics & No. & High-HADS Group ( $n=47)$ & Low-HADS Group $(n=102)$ & Total HADS Score $(n=153)$ \\
\hline $\operatorname{Sex}($ no. $[\%])$ & 149 & & & \\
\hline Female & & $27(57.4)$ & $50(49.0)$ & $77(51.7)$ \\
\hline Male & & $20(42.6)$ & $52(51.0)$ & $72(48.3)$ \\
\hline Age in yrs (mean \pm SD) & 149 & $46.2 \pm 6.4$ & $47.3 \pm 6.9$ & $47.0 \pm 6.7$ \\
\hline Treatment (no. [\%]) & 149 & & & \\
\hline ADR & & $26(55.3)$ & $54(52.9)$ & $80(53.7)$ \\
\hline Fusion & & $21(44.7)$ & $48(47.1)$ & $69(46.3)$ \\
\hline Smoker (no. [\%]) & 146 & $19(40.4)[0]$ & $27(27.3)[3]$ & $46(31.5)$ \\
\hline Pension (no. [\%]) & 145 & $1(2.1)[0]$ & $0(0.0)[4]$ & $1(0.7)$ \\
\hline Unemployed (no. [\%]) & 146 & $10(21.3)[0]$ & $8(8.1)[3]$ & $18(12.3)$ \\
\hline Sick leave (no. [\%]) & 144 & $29(61.7)[0]$ & $43(46.2)[9]$ & $72(51.4)$ \\
\hline Disability pension (no. [\%]) & 143 & $30(63.8)[0]$ & $60(61.9)[5]$ & $90(63.0)$ \\
\hline Heavy work (no. [\%]) & 145 & $32(69.6)[1]$ & $92(92.9)[3]$ & $124(85.5)$ \\
\hline Regular exercise (no. [\%]) & 146 & $13(27.7)[0]$ & $40(40.4)[3]$ & $53(36.3)$ \\
\hline HADS score (mean \pm SD) & 149 & & & \\
\hline Depression & & $8.3 \pm 3.1$ & $3.3 \pm 2.5$ & $4.9 \pm 3.6$ \\
\hline Anxiety & & $11.7 \pm 2.8$ & $4.9 \pm 2.5$ & $7.0 \pm 4.1$ \\
\hline Total & & $20.0 \pm 4.4$ & $8.2 \pm 4.3$ & $11.9 \pm 7.0$ \\
\hline NDI score (mean \pm SD) & 146 & $68.1 \pm 16.5[0]$ & $60.8 \pm 14.6[3]$ & $63.2 \pm 15.6$ \\
\hline Levels (no. [\%]) & 149 & & & \\
\hline 1 & & $35(74.5)$ & $69(67.6)$ & $104(69.8)$ \\
\hline 2 & & $12(25.5)$ & $33(32.4)$ & $45(30.2)$ \\
\hline
\end{tabular}

groups are also presented with a $95 \% \mathrm{CI}$. A positive mean difference corresponds to higher values in the high-HADS group than in the low-HADS group. In contrast to NDI scores, lower values for the EQ-5D indicate a worse quality of life; hence, a negative mean difference corresponds to lower values, which reflect a worse quality of life for the high-HADS group than for the low-HADS group.

As a complement, the Spearman rank correlations between the variables we identified as interesting predictors, HADS-total (including HADS-a and HADS-d) and the preoperative outcome measurement, the NDI score, are reported with the Spearman coefficient together with a $\mathrm{p}$ value for the null hypothesis of no association. The purpose of this subsection was to study the association between these predictors by determining if the same patients had high values for both scores.

All statistical analyses were performed in $\mathrm{R}$ 3.1.0 (2014), packages x86_64, w64, and mingw32 (http:// www.R-project.org).

\section{Results}

The patient-inclusion flow chart is presented in Fig. 1. We randomly assigned 153 patients to undergo ADR $(\mathrm{n}=$ $83)$ or fusion $(\mathrm{n}=70)$. There were 78 women and 75 men with a mean age of 47 years (range 31-60 years) (Table 2). Five patients had a comorbidity (hypertension alone was not accounted for); 3 patients had heart disease, and 2 had been treated for cancer. The mean follow-up duration was
TABLE 4. Results (regression coefficients) from the prediction analysis with HADS-a and HADS-d separately, imputed data

\begin{tabular}{|c|c|c|c|c|}
\hline Variable & Reference & Level & $\begin{array}{l}\text { Regression Coefficient } \\
\qquad(95 \% \mathrm{Cl})\end{array}$ & $\begin{array}{c}\mathrm{p} \\
\text { Value }\end{array}$ \\
\hline Sex & Female & Male & $1.05(-5.93$ to 8.02$)$ & 0.77 \\
\hline Age & & By 1 unit & $-0.27(-0.80$ to 0.26$)$ & 0.31 \\
\hline $\begin{array}{l}\text { Allocated } \\
\text { treatment }\end{array}$ & Fusion & ADR & $3.45(-3.41$ to 10.32$)$ & 0.32 \\
\hline Smoking & No & Yes & $2.10(-6.24$ to 10.44$)$ & 0.62 \\
\hline Pension & No & Yes & $2.44(-38.57$ to 43.44$)$ & 0.91 \\
\hline Unemployed & No & Yes & $-0.68(-13.07$ to 11.69$)$ & 0.91 \\
\hline Sick leave & No & Yes & $-0.47(-9.25$ to 8.32$)$ & 0.92 \\
\hline $\begin{array}{l}\text { Disability pen- } \\
\text { sion }\end{array}$ & No & Yes & $3.50(-6.18$ to 13.18$)$ & 0.47 \\
\hline Strenuous job & No & Yes & $-2.79(-15.82$ to 10.24$)$ & 0.67 \\
\hline $\begin{array}{l}\text { Neck pain } \\
\text { duration }\end{array}$ & & By 1 unit & $5.17(-0.34$ to 10.67$)$ & 0.066 \\
\hline $\begin{array}{l}\text { Arm pain } \\
\text { duration }\end{array}$ & & By 1 unit & $0.92(-5.35$ to 7.19$)$ & 0.77 \\
\hline $\begin{array}{l}\text { Regular } \\
\text { exercise }\end{array}$ & No & Yes & $-3.82(-11.26$ to 3.61$)$ & 0.31 \\
\hline HADS-a score & & By 1 unit & $0.74(-0.39$ to 1.87$)$ & 0.20 \\
\hline HADS-d score & & By 1 unit & $0.79(-0.53$ to 2.11$)$ & 0.24 \\
\hline NDI score & & By 1 unit & $0.25(-0.01$ to 0.50$)$ & 0.063 \\
\hline Levels, $1 / 2$ & 1 & 2 & $-0.75(-8.41$ to 6.90$)$ & 0.85 \\
\hline
\end{tabular}


TABLE 5. Results (regression coefficients) from the prediction analysis with HADS total, imputed data

\begin{tabular}{|c|c|c|c|c|}
\hline Variable & Reference & Level & $\begin{array}{l}\text { Regression Coefficient } \\
\qquad(95 \% \mathrm{Cl})\end{array}$ & $\begin{array}{c}\mathrm{p} \\
\text { Value }\end{array}$ \\
\hline Sex & Female & Male & $1.05(-5.89$ to 7.99$)$ & 0.76 \\
\hline Age & & By 1 unit & $-0.27(-0.80$ to 0.25$)$ & 0.31 \\
\hline $\begin{array}{l}\text { Allocated } \\
\text { treatment }\end{array}$ & Fusion & ADR & $3.45(-3.39$ to 10.29$)$ & 0.32 \\
\hline Smoking & No & Yes & $2.11(-6.20$ to 10.42$)$ & 0.62 \\
\hline Pension & No & Yes & $2.46(-38.48$ to 43.39$)$ & 0.91 \\
\hline Unemployed & No & Yes & $-0.68(-13.02$ to 11.65$)$ & 0.91 \\
\hline Sick leave & No & Yes & $-0.46(-9.22$ to 8.31$)$ & 0.92 \\
\hline $\begin{array}{l}\text { Disability } \\
\text { pension }\end{array}$ & No & Yes & $3.50(-6.15$ to 13.15$)$ & 0.47 \\
\hline Strenuous job & No & Yes & $-2.79(-15.78$ to 10.20$)$ & 0.67 \\
\hline $\begin{array}{l}\text { Neck pain } \\
\text { duration }\end{array}$ & & By 1 unit & $5.19(-0.19$ to 10.57$)$ & 0.059 \\
\hline $\begin{array}{l}\text { Arm pain } \\
\text { duration }\end{array}$ & & By 1 unit & $0.90(-5.29$ to 7.09$)$ & 0.77 \\
\hline $\begin{array}{l}\text { Regular } \\
\quad \text { exercise }\end{array}$ & No & Yes & $-3.82(-11.24$ to 3.59$)$ & 0.31 \\
\hline $\begin{array}{l}\text { HADS total } \\
\text { score }\end{array}$ & & By 1 unit & $0.76(-0.19$ to 1.33$)$ & 0.009 \\
\hline NDI score & & By 1 unit & $0.25(-0.01$ to 0.50$)$ & 0.060 \\
\hline Levels, $1 / 2$ & 1 & 2 & $-0.77(-8.37$ to 6.83$)$ & 0.84 \\
\hline
\end{tabular}

66 months (range 57-77 months). Nine patients in each group failed to report their NDI score at the 5-year followup visit. The cervical levels involved were allocated within the patient groups as follows: C4-C5, 4 (3\%); C5-C6, 50 (33\%); C6-C7, 50 (33\%); C7-T1, 1 (1\%); C4-C6, 4 (3\%); and C5-C7, 44 (29\%).
The high-HADS group included more patients who were smokers (19 of 47 [40\%]) and who exercised less (13 of 47 [28\%]) than the low-HADS group (27 of 102 [27\%] and 40 of 102 [40\%], respectively) (Table 3). The HADSa (Spearman coefficient $=0.74,95 \%$ CI -0.39 to 1.87 ; $=0.20)$ and HADS-d (Spearman coefficient $=0.79,95 \%$ $\mathrm{CI}-0.53$ to $2.11 ; \mathrm{p}=0.24)$ scores separately and treatment allocation (Spearman coefficient $=3.45,95 \% \mathrm{CI}$ -3.41 to $10.32 ; \mathrm{p}=0.32$ ) had no effect on the 5-year NDI scores (Table 4). High values on the preoperative HADStotal $($ Spearman coefficient $=0.76,95 \%$ CI 0.19-1.33; $\mathrm{p}=$ 0.009 ) were a negative predictor of outcome (Table 5).

There were $47 / 153$ patients $(31 \%), 26 / 83(31 \%)$ in the ADR group and 21/70 (39\%) in the fusion group, with either a HADS-a or HADS-d score of $\geq 10$ points; $\geq 10$ points is the cutoff value for indicating significant anxiety/depression for patients undergoing spine surgery. ${ }^{12}$ The high-HADS group improved in NDI scores from a mean of 68.1 (95\% CI 63.3-73.0) to 45.8 (95\% CI 39.2-52.5), and the low-HADS group improved from a mean of 60.4 (95\% CI 57.5-63.3) to 29.1 (95\% CI 25.0-33.3) (Fig. 2); the mean difference in improvement between the groups was 13.4 (95\% CI 5.7-21.2; p < 0.001) (Table 6). We also found differences between groups in EQ-5D $(-0.16,95 \%$ CI -0.29 to $-0.03 ; \mathrm{p}=0.014)$ and VAS-neck $(13.3,95 \%$ CI 3.7-22.9; $\mathrm{p}=0.007$ ) scores but no difference between groups in VAS-arm scores $(7.0,95 \% \mathrm{CI}-2.3$ to $16.4 ; \mathrm{p}=$ 0.14) (Table 6).

The correlation analysis revealed that the patients with higher HADS-total (Spearman coefficient 0.44), HADSa (Spearman coefficient 0.34), and HADS-d (Spearman coefficient 0.50$)$ scores also had higher preoperative NDI scores $(\mathrm{p}<0.001)$; hence, the mentally distressed patients scored the same as the more disabled patients. We found a correlation between the anxious and the depressed patients, indicating that it was more likely to have high scores on both scales (Spearman coefficient 0.67; $\mathrm{p}=0.001$ ).
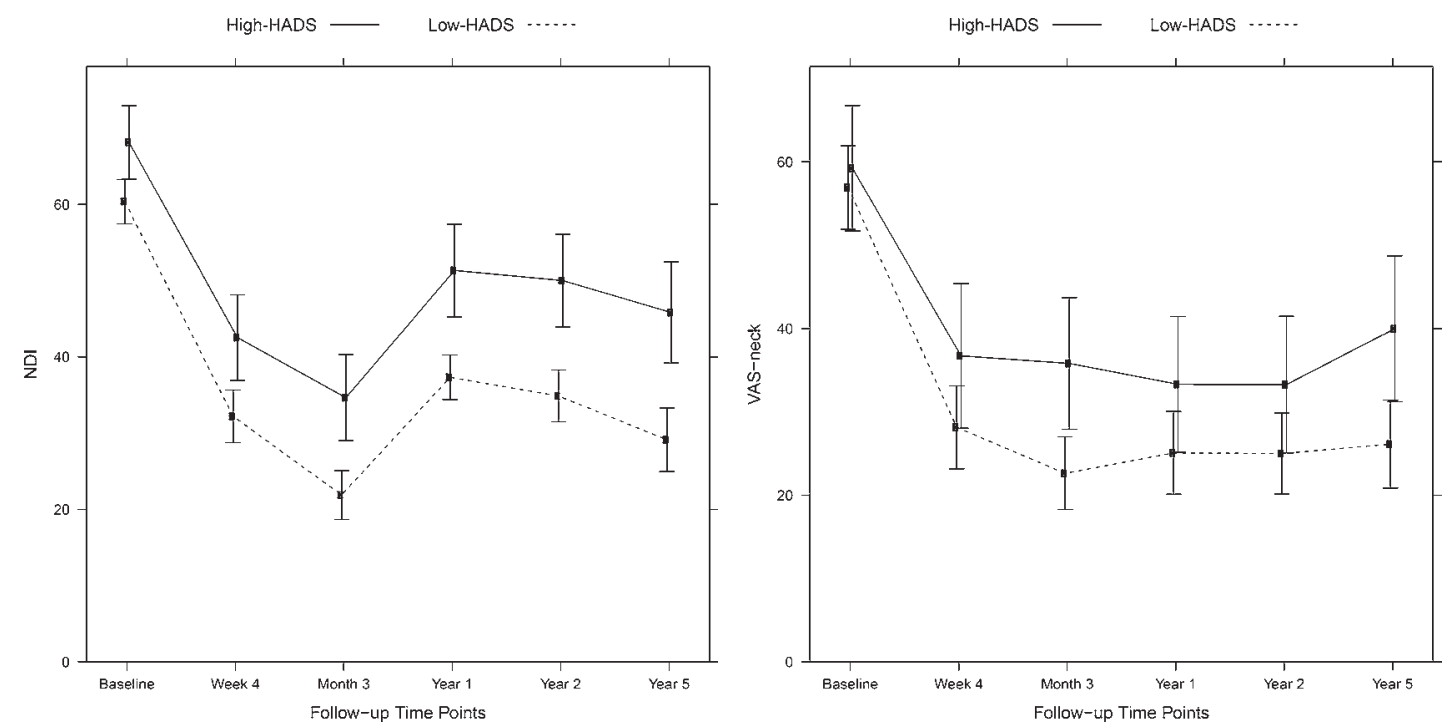

FIG. 2. Imputed data, ITT analysis of the high versus low HADS scores. The time-plot diagram shows the mean values of the NDI (left) and VAS-neck (right) scores at each time point. Error bars, 95\% Cls. 


\section{Discussion}

The post hoc analysis of our RCT revealed that anxiety and depression but not treatment modality had a negative effect on surgical treatment outcome even after 5 years of follow-up. Variables that have been reported previously ${ }^{11,16}$ to be important predictors (e.g., smoking and sex) did not affect long-term outcomes in our study, even though the mentally distressed patients in our study were more likely to be smokers.

In a previous post hoc study, which investigated the association between patients with a high HADS score and female sex, we did not find women to be more depressed than men. ${ }^{23}$ Conflicting results among previous studies regarding the role of women/men and positive/negative outcomes have been found..$^{11,16}$ One theory is that sex might be a confounder and we instead need to investigate something else, such as mental distress. ${ }^{42}$ Mutual mechanisms and comorbidity between pain and depressive disorders seem to exist. ${ }^{14}$ Passive coping has been reported to be a risk factor for disabling neck pain. ${ }^{25}$ Hence, finding these patients with risk factors before surgery might enable early interventions to enhance treatment success. ${ }^{35}$

The results from our study suggest that more attention should be paid to the mental distress of patients, because they had an inferior outcome after long-term follow-up. The high-HADS patients also improved after surgical treatment and therefore should not be denied this treatment option, but other resources such as multidisciplinary care should be considered. The fact that most study reports on fusion versus arthroplasty did not present any convincing differences in long-term outcomes among treatment modalities $^{6,9,31}$ indicates that further research about additional treatment and intervention regarding psychological/ mental factors in the pain experience and coping mechanisms might be more useful for improving outcome., ${ }^{1,10,35}$

Most studies on patients with a cervical spine condition have reported associations between mental disability and less improvement after surgical treatment, even though the follow-up periods were short. ${ }^{2,15,21,30}$ Interesting to note is that Mayo et al..$^{24}$ failed to find such associations, which could be explained by the very short follow-up period (only 6 months) in that study. Persson and Lilja ${ }^{29}$ discovered that although the patients in their study used active coping before surgery, they developed passive coping mechanisms after surgery to treat cervical radiculopathy; the authors therefore recommended a multidisciplinary rehabilitation program that includes cognitive behavioral therapy groups.

Vadivelu et al..$^{42}$ summarized the relationship between pain and psychology and explained that pain and mood have comparable neuroanatomical substrates and neurobiological mechanisms. The regions in the brain associated with the emotional and sensory responses to pain and the regions affected by depression overlap anatomically. The same dysregulation of dopamine and serotonin is common with both chronic pain and depression. Depressed patients show greater emotional reactivity, which can lead to a diminished ability to regulate pain. Hence, patients with preoperative depression need more analgesics after surgery than nondepressed patients. Also, anxiety seems to play an important role in pain perception and triggers the same

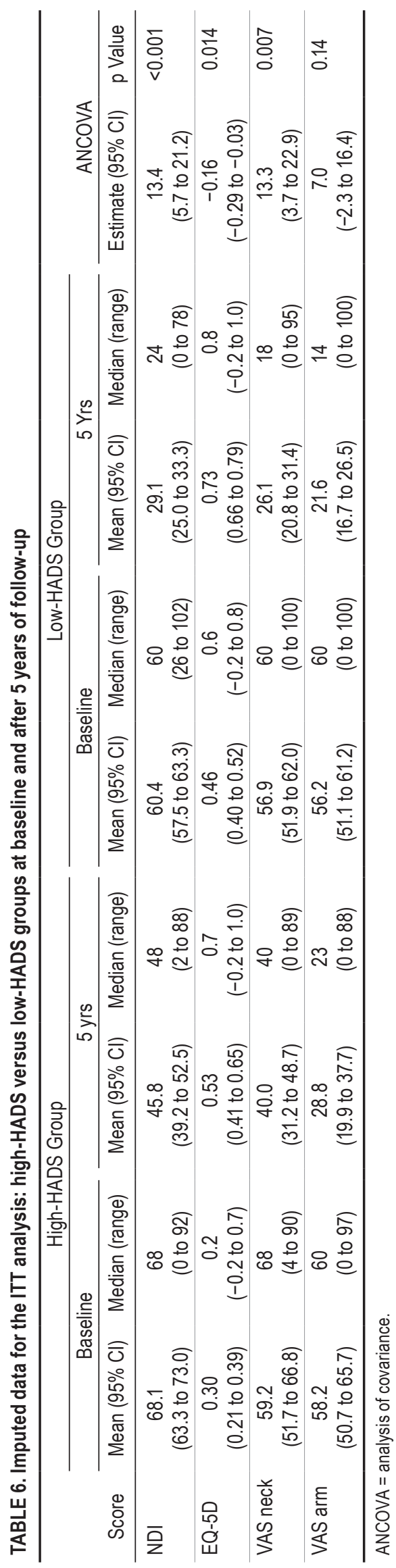

J Neurosurg Spine Volume 29 • October 2018 
synapses in the cortex as chronic pain and therefore can contribute to potentiation of the pain experience. ${ }^{20,34}$

Our study has several strengths. First, we had a longterm follow-up period of 5 years. Second, the follow-up rate after 5 years was $88 \%$, and we used multiple imputation to perform an ITT analysis for the primary outcome. Third, patients and surgeons were blinded to results from the PROMs both before surgery and at the follow-up visits; thus, they were not influenced during decision making or reporting on the patients' health status.

Our study also has some limitations that merit discussion. First, we did not use the HADS at the follow-up visits after surgery. Hence, we do not know what happened with the high HADS scores (i.e., if they remained high in the patients who had them or if they normalized after surgery). Second, the patients had no diagnosis of depression and were not asked about their use of antidepressants. A more thorough investigation about the patients' psychiatric history and medication would have been useful. Third, the HADS was designed as a screening instrument, not a diagnostic tool. Because of the comorbidity of anxiety and depression, uncertainty regarding the ability of these scales to discriminate between the 2 symptoms has been discussed. ${ }^{27}$ A fourth limitation is that this was a post hoc study of an RCT, and so the results do not have the same strength as those based on the RCT's primary outcome variable.

\section{Conclusions}

We found the HADS score, but not allocated treatment, to be a useful instrument for finding patients with a lower level of improvement after surgical treatment for cervical radiculopathy. Recognizing these patients who are likely to improve less is important so that extra attention and better treatment strategies can be considered to prevent secondary long-term complications. More research on the effects of interventions and specialized care to achieve better results in these patients is needed.

\section{Acknowledgments}

We thank Anna Arvidsson and Eva Gulle of the Stockholm Spine Center for collecting/handling data and always assisting and Håkan Löfgren and Ludek Vavruch of the Hospital of Jönköping for contributing with patients and collecting data.

\section{References}

1. Adogwa O, Elsamadicy AA, Cheng J, Bagley C: Pretreatment of anxiety before cervical spine surgery improves clinical outcomes: a prospective, single-institutional experience. World Neurosurg 88:625-630, 2016

2. Alvin MD, Miller JA, Lubelski D, Nowacki AS, Scheman J, Mathews M, et al: The impact of preoperative depression and health state on quality-of-life outcomes after anterior cervical diskectomy and fusion. Global Spine J 6:306-313, 2016

3. Anderson PA, Subach BR, Riew KD: Predictors of outcome after anterior cervical discectomy and fusion: a multivariate analysis. Spine (Phila Pa 1976) 34:161-166, 2009

4. Beesdo K, Hoyer J, Jacobi F, Low NC, Höfler M, Wittchen HU: Association between generalized anxiety levels and pain in a community sample: evidence for diagnostic specificity. J Anxiety Disord 23:684-693, 2009

5. Block AR, Ben-Porath YS, Marek RJ: Psychological risk factors for poor outcome of spine surgery and spinal cord stimu- lator implant: a review of the literature and their assessment with the MMPI-2-RF. Clin Neuropsychol 27:81-107, 2013

6. Burkus JK, Haid RW Jr, Traynelis VC, Mummaneni PV: Long-term clinical and radiographic outcomes of cervical disc replacement with the Prestige disc: results from a prospective randomized controlled clinical trial. J Neurosurg Spine 13:308-318, 2010

7. Carreon LY, Glassman SD, Campbell MJ, Anderson PA: Neck Disability Index, short form-36 physical component summary, and pain scales for neck and arm pain: the minimum clinically important difference and substantial clinical benefit after cervical spine fusion. Spine J 10:469-474, 2010

8. Chin-See-Chong TC, Gadjradj PS, Boelen RJ, Harhangi BS: Current practice of cervical disc arthroplasty: a survey among 383 AOSpine International members. Neurosurg Focus 42(2):E8, 2017

9. Delamarter RB, Zigler J: Five-year reoperation rates, cervical total disc replacement versus fusion, results of a prospective randomized clinical trial. Spine (Phila Pa 1976) 38:711-717, 2013

10. Elsamadicy AA, Adogwa O, Cheng J, Bagley C: Pretreatment of depression before cervical spine surgery improves patient $x$ perception of postoperative health status: a retrospective, single institutional experience. World Neurosurg 87:214219, 2016

11. Engquist M, Löfgren H, Öberg B, Holtz A, Peolsson A, Söderlund A, et al: Factors affecting the outcome of surgical versus nonsurgical treatment of cervical radiculopathy, a randomized controlled study. Spine (Phila Pa 1976) 40:1553-1563, 2015

12. Falavigna A, Righesso O, Teles AR, Baseggio N, Velho MC, Ruschel LG, et al: Depression Subscale of the Hospital Anxiety and Depression Scale applied preoperatively in spinal surgery. Arq Neuropsiquiatr 70:352-356, 2012

13. Frankel HL, Hancock DO, Hyslop G, Melzak J, Michaelis LS, Ungar GH, et al: The value of postural reduction in the initial management of closed injuries of the spine with paraplegia and tetraplegia. I. Paraplegia 7:179-192, 1969

14. Gerrits MM, van Oppen P, Leone SS, van Marwijk HW, van der Horst HE, Penninx BW: Pain, not chronic disease, is associated with the recurrence of depressive and anxiety disorders. BMC Psychiatry 14:187, 2014

15. He J, Xiong W, Li F, Luo W, Gao SC: Depression influences pain and function after cervical disc arthroplasty. J Neurosurg Sci 61:39-45, 2017

16. Hermansen A, Hedlund R, Vavruch L, Peolsson A: Positive predictive factors and subgroup analysis of clinically relevant improvement after anterior cervical decompression and fusion for cervical disc disease: a 10- to 13-year follow-up of a prospective randomized study: clinical article. J Neurosurg Spine 19:403-411, 2013

17. Hernán MA, Hernández-Díaz S, Werler MM, Mitchell AA: Causal knowledge as a prerequisite for confounding evaluation: an application to birth defects epidemiology. Am J Epidemiol 155:176-184, 2002

18. Herrmann C: International experiences with the Hospital Anxiety and Depression Scale-a review of validation data and clinical results. J Psychosom Res 42:17-41, 1997

19. Hilibrand AS, Carlson GD, Palumbo MA, Jones PK, Bohlman HH: Radiculopathy and myelopathy at segments adjacent to the site of a previous anterior cervical arthrodesis. $\mathbf{J}$ Bone Joint Surg Am 81:519-528, 1999

20. Koga K, Descalzi G, Chen T, Ko HG, Lu J, Li S, et al: Coexistence of two forms of LTP in ACC provides a synaptic mechanism for the interactions between anxiety and chronic pain. Neuron 85:377-389, 2015

21. Li S, Qi M, Yuan W, Chen H: The impact of the depression and anxiety on prognosis of cervical total disc replacement. Spine (Phila Pa 1976) 40:E266-E271, 2015 
22. MacDermid JC, Walton DM, Avery S, Blanchard A, Etruw E, McAlpine C, et al: Measurement properties of the neck disability index: a systematic review. J Orthop Sports Phys Ther 39:400-417, 2009

23. MacDowall A, Skeppholm M, Robinson Y, Olerud C: Validation of the visual analog scale in the cervical spine. J Neurosurg Spine 28:227-235, 2018

24. Mayo BC, Massel DH, Bohl DD, Narain AS, Hijji FY, Long WW, et al: Preoperative mental health status may not be predictive of improvements in patient-reported outcomes following an anterior cervical discectomy and fusion. J Neurosurg Spine 26:177-182, 2017

25. Mercado AC, Carroll LJ, Cassidy JD, Côté P: Passive coping is a risk factor for disabling neck or low back pain. Pain 117:51-57, 2005

26. Nesterenko SO, Riley LH III, Skolasky RL: Anterior cervical discectomy and fusion versus cervical disc arthroplasty: current state and trends in treatment for cervical disc pathology. Spine (Phila Pa 1976) 37:1470-1474, 2012

27. Norton S, Cosco T, Doyle F, Done J, Sacker A: The Hospital Anxiety and Depression Scale: a meta confirmatory factor analysis. J Psychosom Res 74:74-81, 2013

28. Parker SL, Godil SS, Shau DN, Mendenhall SK, McGirt MJ: Assessment of the minimum clinically important difference in pain, disability, and quality of life after anterior cervical discectomy and fusion: clinical article. J Neurosurg Spine 18:154-160, 2013

29. Persson LC, Lilja A: Pain, coping, emotional state and physical function in patients with chronic radicular neck pain. A comparison between patients treated with surgery, physiotherapy or neck collar-a blinded, prospective randomized study. Disabil Rehabil 23:325-335, 2001

30. Phan K, Moran D, Kostowski T, Xu R, Goodwin R, Elder B, et al: Relationship between depression and clinical outcome following anterior cervical discectomy and fusion. J Spine Surg 3:133-140, 2017

31. Phillips FM, Geisler FH, Gilder KM, Reah C, Howell KM, McAfee PC: Long-term outcomes of the US FDA IDE prospective, randomized controlled clinical trial comparing PCM cervical disc arthroplasty with anterior cervical discectomy and fusion. Spine (Phila Pa 1976) 40:674-683, 2015

32. Pool JJ, Ostelo RW, Hoving JL, Bouter LM, de Vet HC: Minimal clinically important change of the Neck Disability Index and the Numerical Rating Scale for patients with neck pain. Spine (Phila Pa 1976) 32:3047-3051, 2007

33. Ranawat CS, O'Leary P, Pellicci P, Tsairis P, Marchisello P, Dorr L: Cervical spine fusion in rheumatoid arthritis. J Bone Joint Surg Am 61:1003-1010, 1979

34. Rhudy JL, Meagher MW: Fear and anxiety: divergent effects on human pain thresholds. Pain 84:65-75, 2000

35. Ris I, Søgaard K, Gram B, Agerbo K, Boyle E, Juul-Kristensen B: Does a combination of physical training, specific exercises and pain education improve health-related quality of life in patients with chronic neck pain? A randomised control trial with a 4-month follow up. Man Ther 26:132-140, 2016

36. Skeppholm M: The value of artificial disc replacement in cervical radiculopathy [thesis]. Stockholm: Karolinska Institutet, 2014

37. Skeppholm M, Fransson R, Hammar M, Olerud C: The association between preoperative mental distress and patientreported outcome measures in patients treated surgically for cervical radiculopathy. Spine J 17:790-798, 2017

38. Skeppholm M, Lindgren L, Henriques T, Vavruch L, Löfgren $\mathrm{H}$, Olerud C: The Discover artificial disc replacement versus fusion in cervical radiculopathy-a randomized controlled outcome trial with 2-year follow-up. Spine J 15:1284-1294, 2015

39. Smith GW, Robinson RA: The treatment of certain cervicalspine disorders by anterior removal of the intervertebral disc and interbody fusion. J Bone Joint Surg Am 40-A:607-624, 1958

40. Strömqvist B, Fritzell P, Hägg O, Jönsson B: The Swedish Spine Register: development, design and utility. Eur Spine J 18 (Suppl 3):294-304, 2009

41. Thompson T, Keogh E, French CC, Davis R: Anxiety sensitivity and pain: generalisability across noxious stimuli. Pain 134:187-196, 2008

42. Vadivelu N, Kai AM, Kodumudi G, Babayan K, Fontes M, Burg MM: Pain and psychology - a reciprocal relationship. Ochsner J 17:173-180, 2017

43. White IR, Royston P, Wood AM: Multiple imputation using chained equations: issues and guidance for practice. Stat Med 30:377-399, 2011

44. Young IA, Cleland JA, Michener LA, Brown C: Reliability, construct validity, and responsiveness of the neck disability index, patient-specific functional scale, and numeric pain rating scale in patients with cervical radiculopathy. Am J Phys Med Rehabil 89:831-839, 2010

45. Zigmond AS, Snaith RP: The hospital anxiety and depression scale. Acta Psychiatr Scand 67:361-370, 1983

\section{Disclosures}

Support for this work was provided by institutional research grants from DePuy Synthes, Stockholm County Council, Uppsala County Council, and the Swedish Society of Spinal Surgeons. Dr. MacDowall is on the board of the Swedish Society of Spinal Surgeons. Dr. Skeppholm is a member of the speaker's bureau for DePuy Synthes Spine. Dr. Robinson is on the speaker's bureau and has given paid presentations for DePuy Synthes Spine and Medtronic and is on the board of the Cervical Spine Research Society-European Section and AOSpine Nordic Region. Dr.

Olerud is on the speaker's bureau of Anatomica, AOSpine, DePuy Synthes, and Medtronic and is on the board of the Cervical Spine Research Society-European Section.

\section{Author Contributions}

Conception and design: MacDowall, Skeppholm, Olerud. Acquisition of data: MacDowall. Analysis and interpretation of data: MacDowall. Drafting the article: MacDowall. Critically revising the article: Skeppholm, Robinson, Olerud. Reviewed submitted version of manuscript: MacDowall, Olerud. Approved the final version of the manuscript on behalf of all authors: MacDowall. Statistical analysis: Lindhagen. Study supervision: Skeppholm, Robinson, Olerud.

\section{Supplemental Information}

\section{Previous Presentations}

Portions of this work were presented in abstract form at the Cervical Spine Research Society 45th Annual Meeting held in Hollywood, Florida, on November 30 to December 2, 2017.

\section{Author Correspondence}

Anna MacDowall: Uppsala University, Uppsala, Sweden. anna. mac.dowall@akademiska.se. 